\title{
Building of Peace and Reconciliation
}

\author{
by VERA VOHLÍDALOVÁ
}

Two projects were opened on October 30, 1995 in Dresden under the patronage of both presidents Václav Havel, President of the Czech Republic, and Roman Herzog, President of the Federal Republic of Germany, with the aim to be a step towards furthering peace and good relations between neighbours and as a demonstration of human understanding. These projects were the establishment of regular meetings between Czech and German youth (the first one took place in Polika in September 1996) and the construction of a new building for The Research Library of Liberec on the site where one of the largest synagogues of Central Europe once stood. This synagogue was burnt and completely destroyed by the Nazis during „Kristallnacht“ (Crystal Night) November 9 - 10, 1938.

This project links the library and the synagogue of Liberec in perfect harmony and will give each its own building for the first time in more than 50 years. It is both the first public library with a collection of this size and breadth to be built in the country since 70 years and the first new synagogue to be built in the Czech Republic (former Czechoslovakia) since World War Two. This new building project will present a library as an institution which not only takes care of various documents but also provides information of all kinds: including among other things access to both historical and current information on many cultures, lands and peoples.

A library is a place of cultural and human heritage. The library in Liberec is in a region where multiple cultures have lived and rubbed shoulders for many years with both friendly and productive as well as sometimes tense and awkward relations. The border(s) has/have been formed and shifted, opened and closed repeatedly at the whim of high political powers. The region's complicated history includes the presence of glass-making families whose genealogy often encompasses multiple cultures and backgrounds and who are known worldwide for their precious masterpieces of glass art, as well as of the seat of the local Nazi headquarters during the World War Two (this is 
connected with person of Konrad Henlein). Today the people of the region are trying to reach out and shake hands with others across three borders.

The Jewish House of Prayer, which will be an integral but independent part of this new building, cannot be a substitute for the grand synagogue which originally stood on the site. Regional town authorities and church communities came together in a cooperative effort in 1887 - 1889 to build the former synagogue. This new House of Prayer is to be not only a place of meeting for the Jews of the region but also both a symbol of human understanding and an act of symbolic compensation. It will serve as a reminder that people of various beliefs, colours and cultures have lived, do and will always live in and among us. Thanks to moral and financial support from many sides it is a symbol of joining and of shaking hands over mutually lived history to a shared future.

\section{THE HISTORY OF THE LIBRARY IN LIBEREC}

1902 The first German public library is established in Liberec.

1904 The first Czech public library is founded, combining libraries of Czech associations.

1924 „Bücherei der Deutschen“, the national library of Germans in Bohemia, is opened.

1938 The majority of Czech books is destroyed during the Nazi occupation.

1945 The Czechoslovak state took over the administration of the library.

1947 The right to receive a deposit copy of Czechoslovak publications is granted.

1954 The library (250,000 volumes) is destroyed by fire.

1959 The two public libraries (Czech and former German) are united on January $1^{\text {st }}$.

1990 The library came under the administration of the Ministry of Culture as The Research Library with local, district and regional functions.

\section{THE LIBRARY TODAY}

The Research Library in Liberec is the only public library in Liberec. Its range of services and the size of its collection make it the biggest in Northern 
Bohemia as well as in the neighbouring border regions of Poland and Germany (Saxony).

\section{Universal Services - Available to Everyone}

The library serves especially

- as a local public library with a wide range of non-fiction and popular scientific literature,

- as a district library for neighbouring districts working under the district library authorities for the local public libraries there; the library also operates as the Service and Counseling Centre for these and other types of libraries in the town and district,

- as a regional universal research library with a wide range of printed and audio-visual documents (books, magazines, sheet-music, maps, patents, standards, records and CDs, videos, etc.), the majority of which may be accessed on the electronic database,

- as an information centre for bibliographical and factographical references on the database.

The above mentioned documents and the database mainly serve the public with a wide variety of information but also cover certain specialist areas (i.e., the textile and the glassmaking industries) as well as a wide range of historical and modern regional documents (see below). All in all, the library contains more than one million sources of information.

The library also offers Internet access to its readers.

\section{Special Services - mainly Useful for and Offered to the Public Professional Sector}

The library is a part of a public information service network which reflects the character of the region and identifies strongly with the activities of the Euroregion Nisa, an area encompassing the Czech, Polish and German regions of Northern Bohemia, lower Silesia and south-east Saxony respectively.

The services offered are determined by the information and document resources of the library and also on the needs of current and potential users. 
The special services of the library are primarily focused on Liberec and its surroundings. Because of their uniqueness and scope, however, some of these are of international significance as well. They include for example:

- a collection of historical and current regional books and documents covering Czech-German relations and the German minority in the area which is being put into the database,

- a collection of Germanica in Czech Lands, i.e. documents written by Germans who lived in Czechoslovakia. The material has been put on the database and will also be available in the neighbouring regions of Austria, Germany and Poland as part of a collaborative effort for an ongoing joint catalogue; this work is in essence a continuation and modernisation of the activities of the national library of Germans who lived in Czechoslovakia, „Bücherei der Deutschen“, in the years 1924 - 1945; their holdings are an important starting point for this larger and growing collection, - the Austrian collection (Austriaca).

\section{THE NEW LIBRARY}

This project connects two worlds - the ,library of the past and the „library of the future" - and embodies the changing trend from the traditional library to the multimedia library. The building site is in the upper centre of the town among the other important and frequented buildings such as the town hall, the theatre, the faculty of commerce of the Technical University and the swimming pool. The library itself will be surrounded by greenery - many trees, shrubs and a small park. In its entrance hall there will be an information centre, a registration desk, a gallery, a cloakroom, a small cafe and also lifts and stairs to the other floors. On these upper floors there will be open shelves (with over 200,000 volumes) of non-fiction (in Czech and foreign languages), a research library, a library for children and youth (World of Fantasy), a musical and audio library, a multi-purpose hall, a recording studio and ample space for studying and relaxation connected with reading or listening surrounded by open space and greenery.

The entrance area and gallery, along with other non-library spaces, will be opened independently of the upper library areas. The entrance to the Jewish House of Prayer leads the visitor to an exhibition on the history of the synagogue. The prayer room is on the first floor, and other related areas above. 


\section{Changes and Developments in Services in the New Library}

A very important part of the informational and educational services of a library is that of culture. Culture is not only an uplifting of the human spirit, human art, thought and enjoyment but it also includes the art of basic human understanding, listening to, helping and assisting one another, of knowing oneself as well as others. These essential principles from the heart of the project, and the aim of furthering and enabling their realisation have guided the design of the new library. In this open house it will not only be possible to conduct research but also to read, study, enjoy and connect with the wider world of information through the electronic network.

Documents on various media which are now hidden somewhere in closed areas and presented only in catalogues will be made available to the public on open shelves.

All services and opportunities will be open to all regardless of age, race, disability, or area of interest as well as to the stray visitor looking for information on the town and region or simply for a pleasant respite along the way.

It is the library's goal that each and every visitor's needs will be met, whether for resting places, relaxation, comfortable spaces, refreshment, entertainment or for areas conducive to concentration, study and scientific research.

The reason for this present project is to prepare for the flexibility required in offering a modern, capable and efficient service to the public. The building will be prepared to change and re-arrange its spaces as necessary or desirable according to changing social or cultural requirements.

The emphasis throughout is placed on the visitors freedom of movement according to his or her own individual needs and interests, and on enabling readers to choose how they access information (form), what information they find (content), and how much information they call up and have at their disposal (scope) from the broad range available. 
Numbers and Figures:

\begin{tabular}{|l|l|l|}
\cline { 2 - 3 } \multicolumn{1}{c|}{} & \multicolumn{1}{c|}{ Old building } & \multicolumn{1}{c|}{ New building } \\
\hline units & $1,200,000$ & $\begin{array}{l}1,200,000 \\
(230,000 \text { in free access })\end{array}$ \\
\hline & $\begin{array}{l}3 \text { buildings } \\
5 \text { stores }\end{array}$ & 1 house \\
\hline budget & 400,000 USD/rok & about 800,000 USD \\
\hline area & $7,000 \mathrm{~m}^{2}$ & $\begin{array}{l}\text { Library: } 12,500 \mathrm{~m}^{2} \\
\text { Synagogue: } 245 \mathrm{~m}^{2}\end{array}$ \\
\hline places for users & about 90 & $\begin{array}{l}300 \text { for reading a study } \\
180 \text { in halls }\end{array}$ \\
\hline
\end{tabular}

New building costs:

$$
\begin{aligned}
& \text { 9,000,000,- USD from Czech republic } \\
& 2,000,000,- \text { USD from European Union (for equipment) } \\
& 2,000,000,- \text { USD from the others } \\
& 13,000,000,- \text { USD total (with synagogue) }
\end{aligned}
$$

The new building was financed by the Czech state (Ministry of Culture), European Union through the programme Phare CBC, government of the Federal Republic of Germany, Czech-German Fund of the Future and canton St. Gallen (Switzerland).

Mgr. Vera Vohlídalová

State Research Library in Liberec

nám. Dr. E. Beneše 23

46053 Liberec 1, Czech Republic

Tel./Fax: +420 482710864 (director)

vohlidalova@sykli.cz

<http://www.sykli.cz> 
Building of Peace and Reconciliation

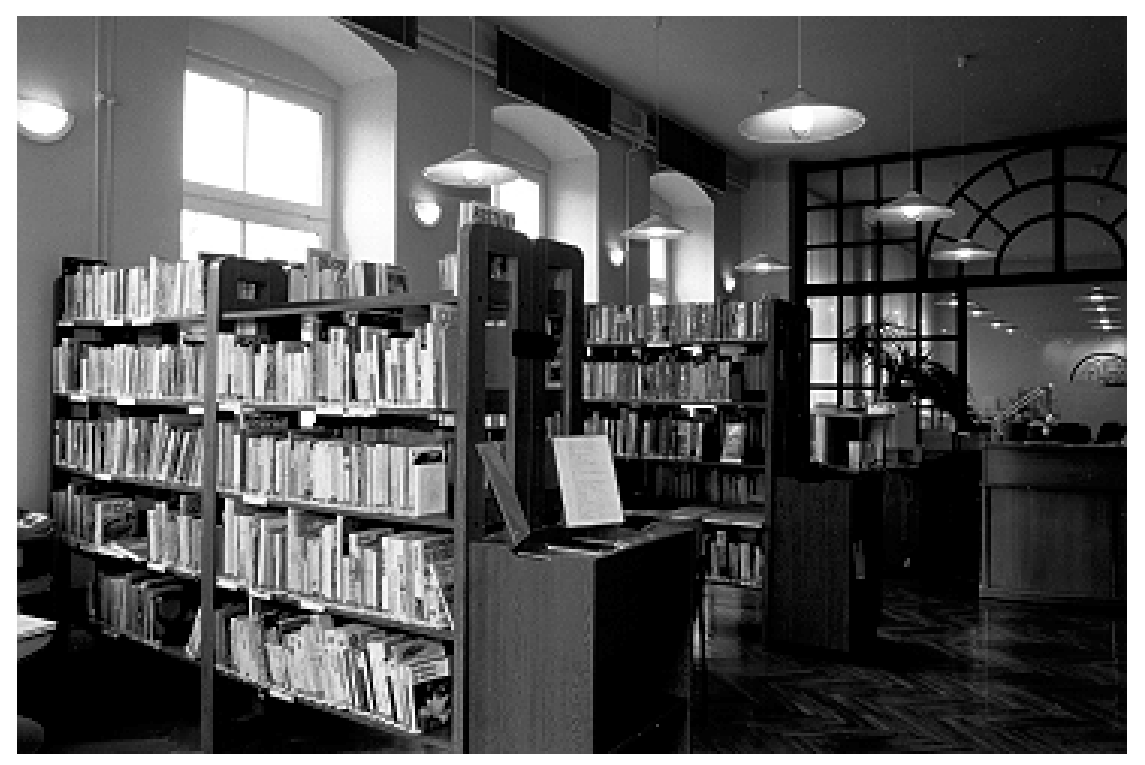

Figure 1

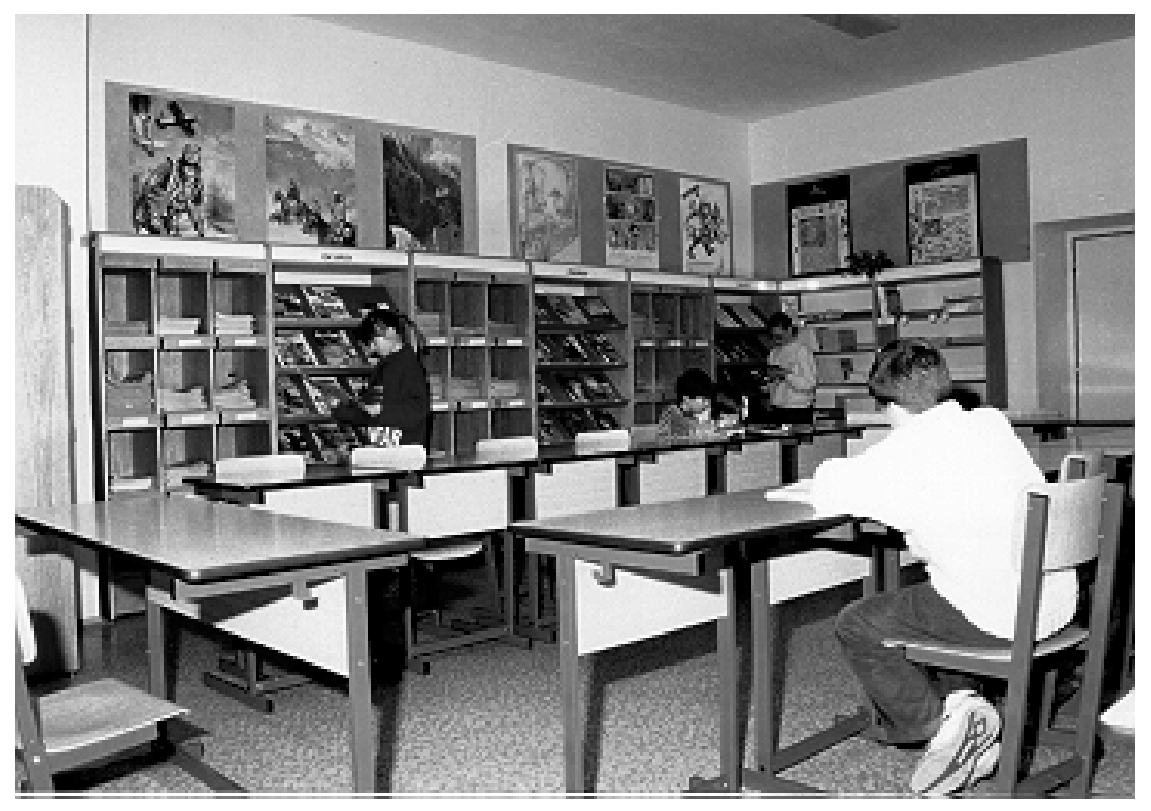

Figure 2 
VERA VOHLÍDALOVÁ

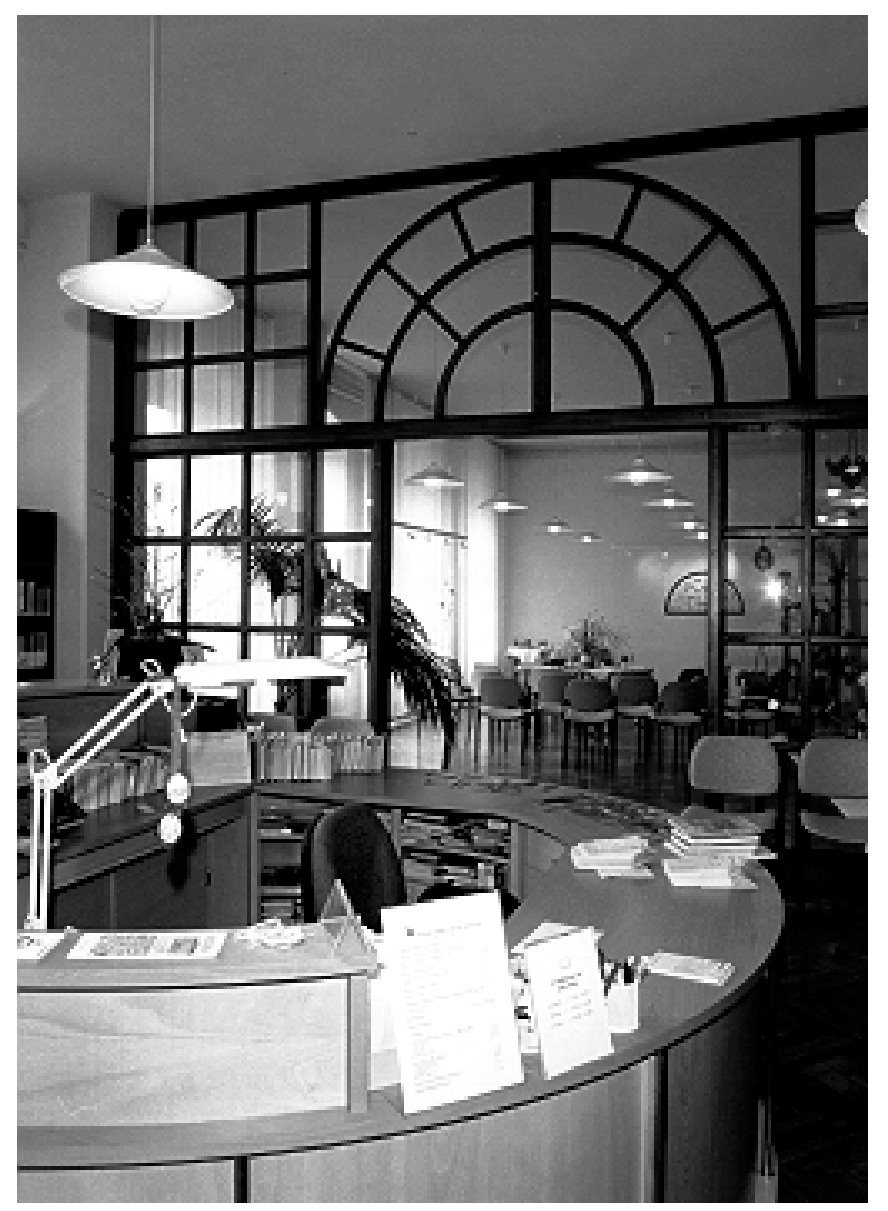

Figure 3 
Building of Peace and Reconciliation

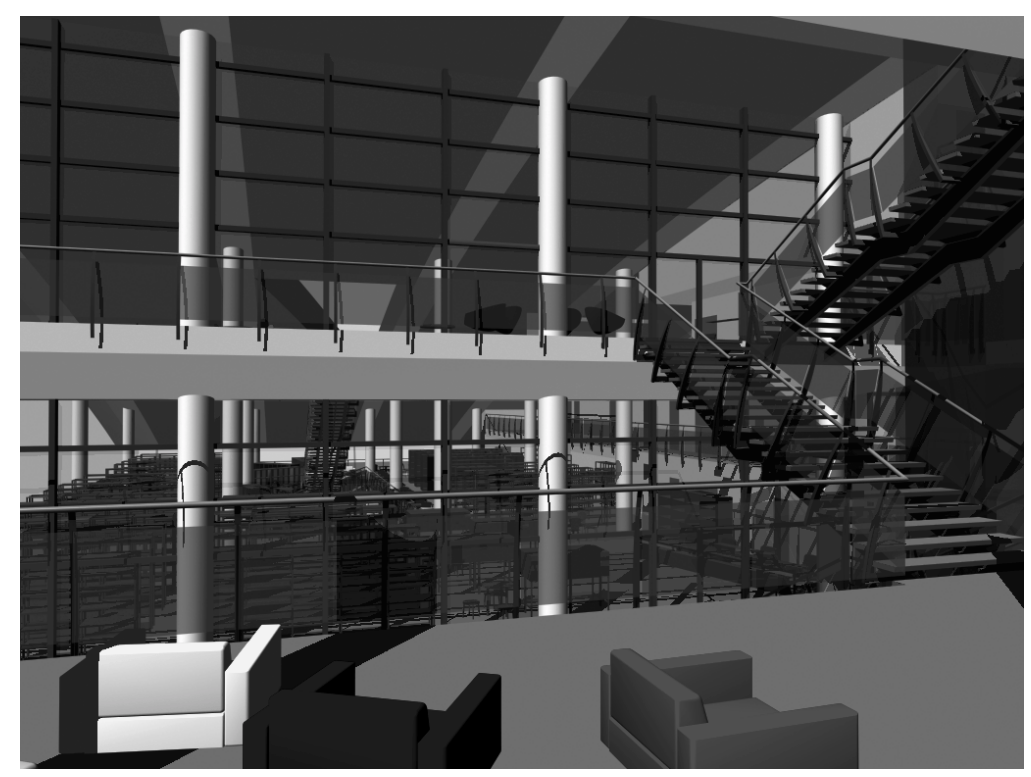

Figure 4

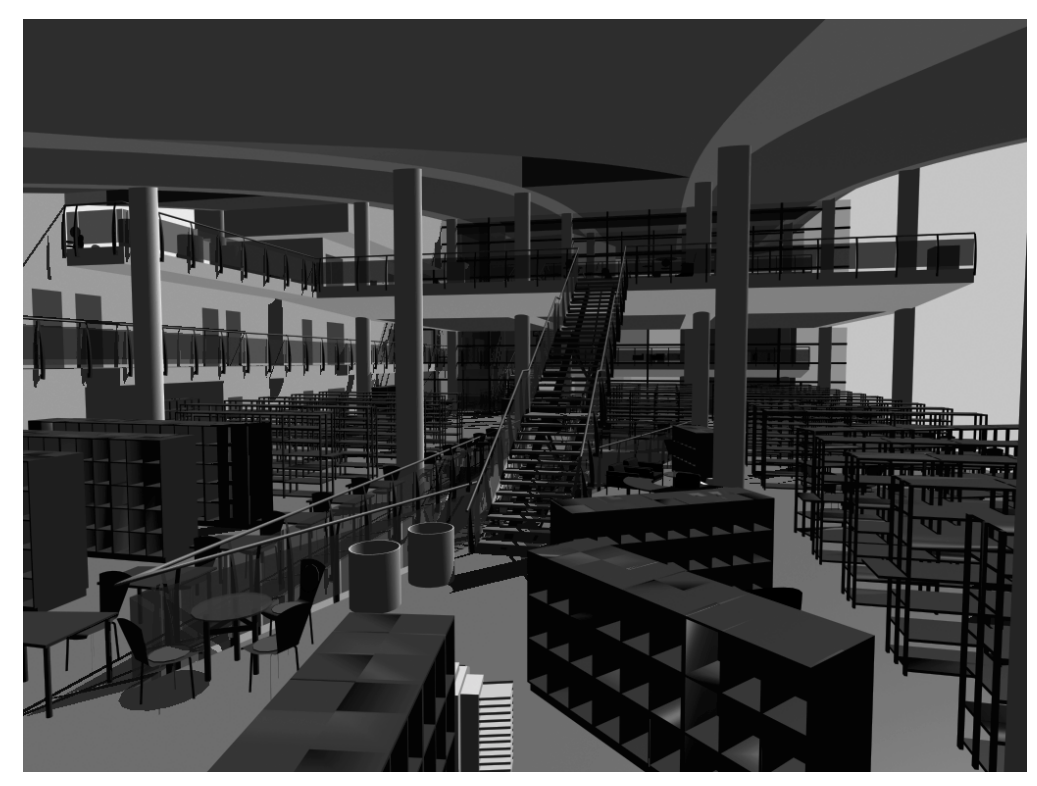

Figure 5 


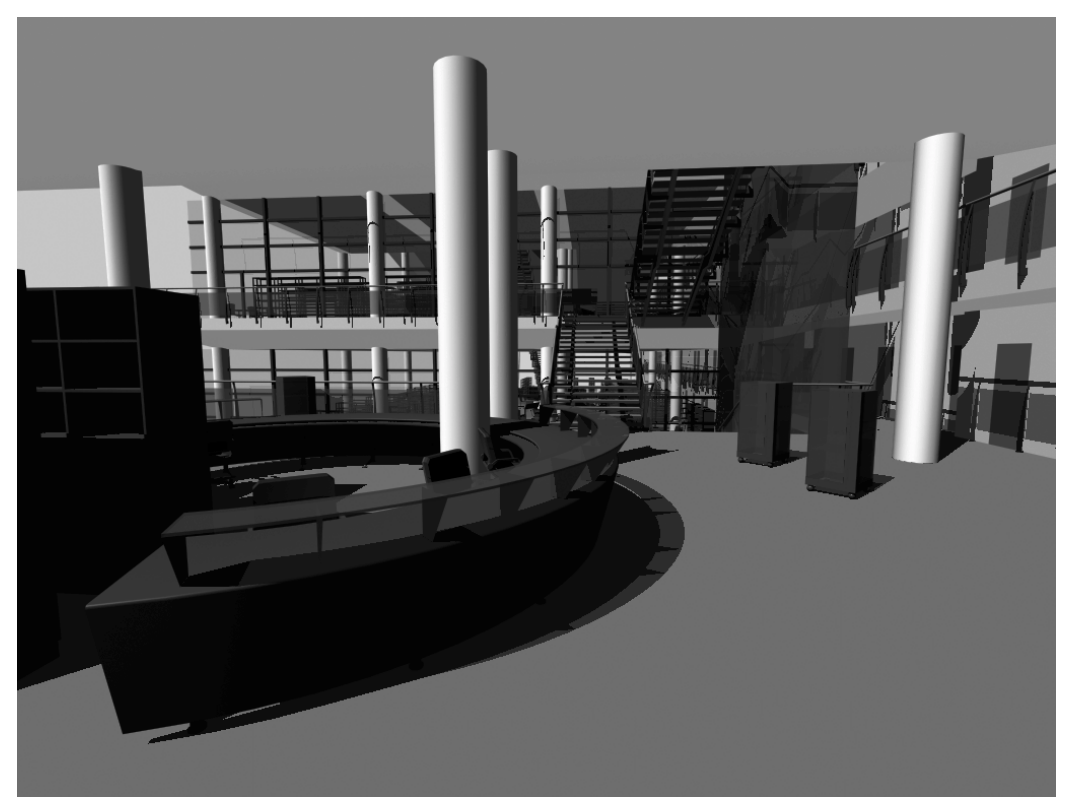

Figure 6

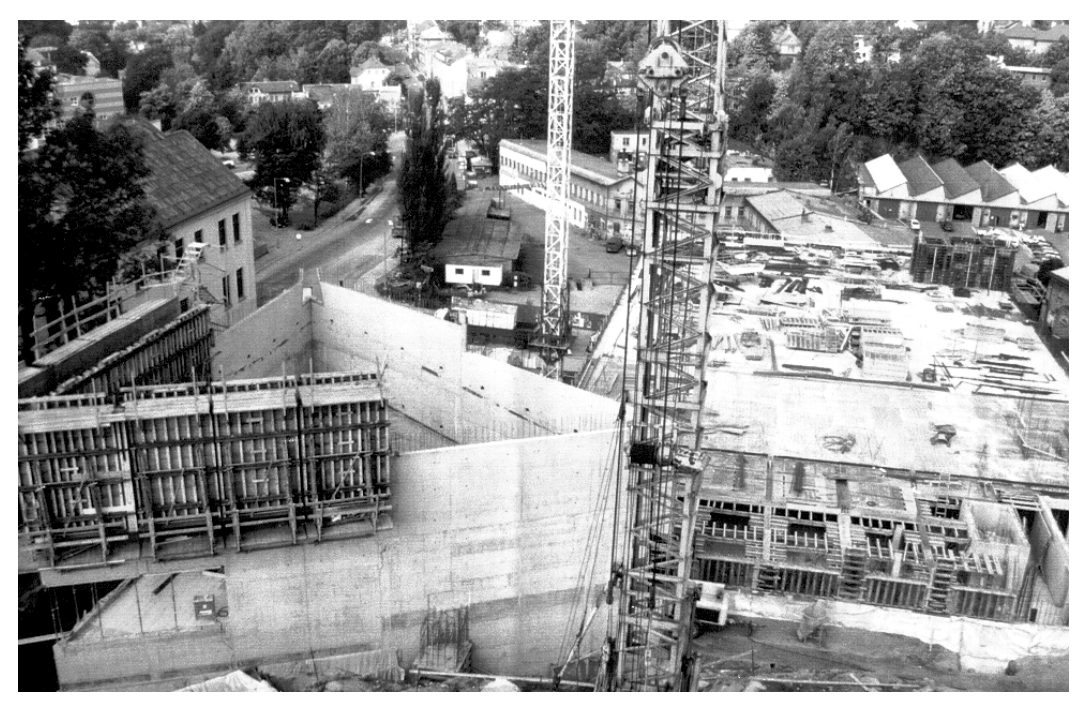

Figure 7 